\title{
Lithium Recovery from Electrodes in Cellphone Batteries through the Leaching Process with Organic Agents Assisted by Ultrasound
}

\author{
Pedro A. Martínez, Juan C. Orozco, Alejandro Alonso, Rosa M. Luna, Miguel A. Barron, \\ Dulce Y. Medina, Elizabeth Garfias-García \\ División de Ciencias Básicas e Ingeniería, Universidad Autónoma Metropolitana, \\ Reynosa Tamaulipas, México \\ Email: bmma@correo.azc.uam.mx
}

How to cite this paper: Martínez, P.A., Orozco, J.C., Alonso, A., Luna, R.M., Barron, M.A., Medina, D.Y. and Garfias-García, E. (2018) Lithium Recovery from Electrodes in Cellphone Batteries through the Leaching Process with Organic Agents Assisted by Ultrasound. Journal of Materials Science and Chemical Engineering, 6, $1-5$.

https://doi.org/10.4236/msce.2018.69001

Received: August 14, 2018

Accepted: September 10, 2018

Published: September 13, 2018

Copyright (c) 2018 by authors and Scientific Research Publishing Inc. This work is licensed under the Creative Commons Attribution International License (CC BY 4.0).

http://creativecommons.org/licenses/by/4.0/

\section{(c) (i) Open Access}

\begin{abstract}
The present work proposes a mean for recovery of metals used in current ion-lithium batteries, like lithium, cobalt and nickel, using organic agents and ultrasound instead of the more aggressive and less environment friendly method with sulfuric acid. This is especially useful in those countries that doesn't have lithium deposits and have a growing demand of such batteries, reducing the economic loss this represents. During the process, variables such as temperature, leaching agent concentration and ultrasound frequency were modified, using concentrations of $0.5 \mathrm{M}$ (molar), $1 \mathrm{M}$ and $1.5 \mathrm{M}$ of sodium citrate, temperatures of $25^{\circ} \mathrm{C}, 55^{\circ} \mathrm{C}$ and $60^{\circ} \mathrm{C}$ and also ultrasound frequencies of $20 \mathrm{KHz}, 30 \mathrm{KHz}$ and $40 \mathrm{KHz}$. It was found that the best combination of these variables that yielded the most quantity of the desired metal was $0.5 \mathrm{M}$ concentration for both lithium and nickel, while using $60^{\circ} \mathrm{C}$ and no ultrasound with $\mathrm{Li}$ and $55^{\circ} \mathrm{C}$ and $40 \mathrm{KHz}$ for $\mathrm{Ni}$. For Co the best variables discovered were 1.5 molar concentration, $60^{\circ} \mathrm{C}$ and $40 \mathrm{KHz}$.
\end{abstract}

\section{Keywords}

Lithium Leaching, Organic Agents, Ion-Lithium Batteries, Ultrasound Leaching, Sodium Citrate

\section{Introduction}

Li-ion batteries (abbreviated as LIB) are a type of electrochemical batteries that are popular for electronic devices all around the world given its high energy density, high capacity, low discharge, good performance and light weight [1]-[6]. 
While there are several types of Li-ion batteries, the most used in electronics (like cellphones) is the one based on lithium cobalt oxide $\left(\mathrm{LiCoO}_{2}\right)$ because of its high energy density. While it possesses high safety risks [7], it is still the best option for consumer electronics which makes the volume of batteries made quite huge, so the volume of waste generated by them is equally high. This, along with some countries wih poor or non-existent lithium deposits, makes recycling an interesting proposal both environmentally and economically, with leaching being the most used method for the recovery of the metals that are part of the aforementioned batteries.

One of the most used leaching processes uses acids such as sulfuric acid, $\mathrm{H}_{2} \mathrm{SO}_{4}$, which are not too healthy for the environment, so the search for alternatives of leaching agents is an active research topic [8] [9] [10] [11] [12]. Organic agents are an alternative to acids given that their enviromental impact is less hazardous and can be easily disposed after being used. The only used in this experiment is sodium citrate, $\mathrm{NaH}_{2}\left(\mathrm{C}_{3} \mathrm{H}_{5} \mathrm{O}(\mathrm{COO})_{3}\right)$, which is the sodium salt in the citrate acid found in the cells of the human body. Ultrasound has become an increasingly used method along with leaching because it is considered that it increases the leaching efficiency and the yield of products [13]. Thus, this process increases the yielded metal residues while reducing the time and amount of leaching agents used to obtain them.

Many works had mentioned high conversions of Co and Li obtained mixing two reagents, citric and ascorbic acids [14], citric, acetic and oxalic acids with hydrogen peroxide [15]. Other authors have shown good results as well using citric acid with hydrogen peroxide [16]; however, the use of other reagents has not increased the Co and Li conversion substantially. Nevertheless, the temperature and the ultrasonic agitation have already improved the results. In the present work the use of the only citrate acid in combination with the ultrasonic process presented.

\section{Methodology}

Batteries were gathered from collection and recycle centers, then they were then disassembled and their components separated in unwanted and useless residues, and useful residues for leaching. The useful residues were prepared for X-Ray Diffraction (XRD) analysis to know which elements were present, while the Atomic Absorption Spectrometry (AAS) technique was employed for characterization. For the leaching process, was used an ultrasonic bath of 3 liter, with temperature control, the concentrations of the organic agent were established in $0.5 \mathrm{M}, 1 \mathrm{M}$ and $1.5 \mathrm{M}$; then, according to the compounds, the leaching process was done changing temperature from $25^{\circ} \mathrm{C}$, to $50^{\circ} \mathrm{C}$ and $60^{\circ} \mathrm{C}$ during the process. Ultrasound frequency was varied using $20 \mathrm{KHz}, 30 \mathrm{KHz}$ and $40 \mathrm{KHz}$. Finally, it was determined the efficiency of the process, quantifying the wanted metal residue yielded after leaching related to the initial amount in the batteries and the agents used. 


\section{Results and Comments}

From the several combinations of the three variables proposed, it was found three specific combinations to be the most optimum for lithium recovery, as is shown in Figure 1. As one can see, the optimal combination of variables for lithium recovery was that with the highest temperature and the lowest leaching agent concentration with no ultrasound, opposite to the initial hypothesis proposed in this work. Nevertheless, this recovery of lithium does not grow after a defined time frame, while the other do that. This means that the other two combinations of variables processes would require more time and resources to yield the same results, therefore costing more economically than the process at the highest temperature with low agent concentration and no ultrasound.

For cobalt and nickel, the recovered quantities where found to be lower than lithium, as is shown in Figure 2, even though this was the methods that yielded the most recovery for both metals, so one can assume that different methods should be used for the recovery of this elements.

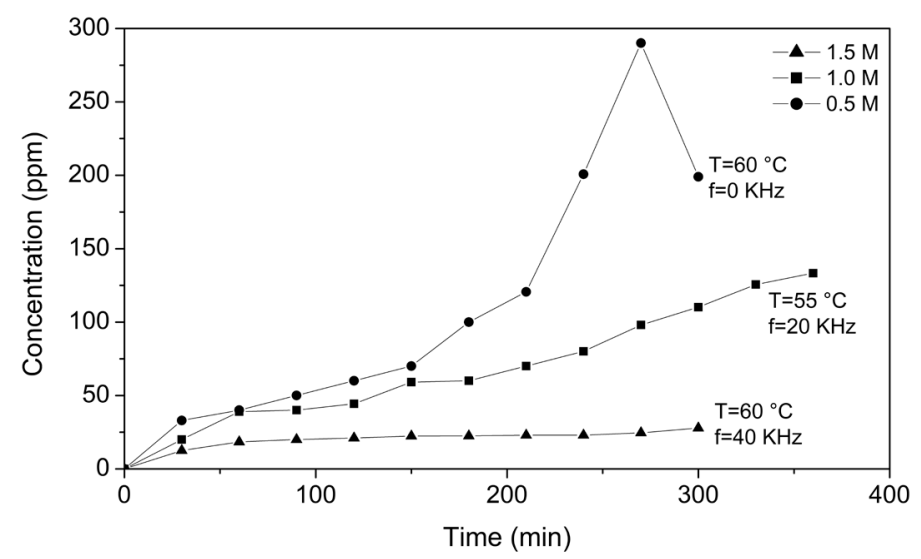

Figure 1. The three best methods for the recovery of lithium showing the variables employed. $0.5 \mathrm{M}$ concentration with no ultrasound and high temperature yielded the best result.

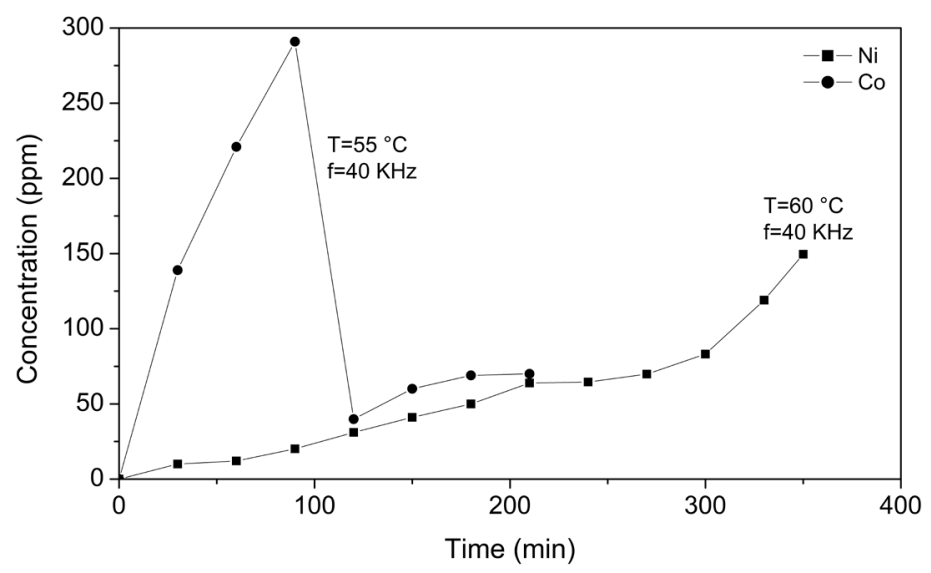

Figure 2. Results obtained for cobalt recovery at $1.5 \mathrm{M}$ concentration and nickel at $0.5 \mathrm{M}$ concentration. 


\section{Conclusions}

This work presents an alternative choice to the known leaching processes based on sulfuric acid, even for metals that are not lithium and that are found in cellphone battery residues. The use of organic agents allows a less harmful impact to the environment and an easy way to handle residues.

The variation of the concentration of the leaching agent enabled to find the best combination of the involved variables, being $0.5 \mathrm{M}$ for lithium and nickel recovery, and $1.5 \mathrm{M}$ for cobalt. It was also seen that the highest temperature used $\left(60^{\circ} \mathrm{C}\right.$ before the organic agent started to evaporate) yielded the highest concentration of the metals recovered.

For ultrasound, the best choice was $40 \mathrm{KHz}$ for all the considered metals, however, in long time intervals, the curves for recovery present increasing growth but they never reach the highest possible efficiency. This indicates that ultrasound contributes to the breaking of the $\mathrm{LiCoO}_{2}$ compound in which the metals are found before leaching. Experiments indicate that the ideal conditions found for a high recovery efficiency, near $86 \%$, are the highest temperature employed of $60^{\circ} \mathrm{C}$ with no ultrasound. Future work must include additional experiments to find the conditions for an efficiency of metals recovery that be economically viable for pilot facilities, besides of testing different organic compounds and higher temperatures.

\section{Conflicts of Interest}

The authors declare no conflicts of interest regarding the publication of this paper.

\section{References}

[1] Speirs, J., Contestabile, M., Houari, Y. and Gross, R. (2014) The Future of Lithium Availability for Electric Vehicle Batteries. Renewable and Sustainable Energy Reviews, 35, 183-193. https://doi.org/10.1016/j.rser.2014.04.018

[2] Grosjean, C., Herrera Miranda, P., Perrin, M. and Poggi, P. (2012) Assessment of World Lithium Resources and Consequences of Their Geographic Distribution on the Expected Development of the Electric Vehicle Industry. Renewable and Sustainable Energy Reviews, 16, 1735-1744. https://doi.org/10.1016/j.rser.2011.11.023

[3] Lee, W.J., Maiti, U.N., Lee, J.M., Lim, J., Han, T.H. and Kim, S.O. (2014) Nitrogen-doped Carbon Nanotubes and Graphene Composite Structures for Energy and Catalytic Applications. Chemical Communications, 50, 6818-6830.

https://doi.org/10.1039/c4cc00146j

[4] Liu, N., Lu, Z., Zhao, J., McDowell, M.T., Lee, H.W., Zhao, W. and Cui, Y. (2014) A Pomegranate-Inspired Nanoscale Design for Large-Volume-Change Lithium Battery Anodes. Nature Nanotechnology, 9, 187-192.

https://doi.org/10.1038/nnano.2014.6

[5] Yoncheva, M., Koleva, V., Mladenov, M., Sendova, M., Nicolaeva, M., Stoyanova, R. and Zhecheva, E. (2011) Carbon-Coated Nano-Sized $\mathrm{LiFe}_{1-\mathrm{x}} \mathrm{Mn}_{\mathrm{x}} \mathrm{PO}_{4}$ Solid Solutions $(0 \leq x \leq 1)$ Obtained from Phosphate-Formate Precursors. Journal of Materials Science, 46, 7082-7089. https://doi.org/10.1007/s10853-011-5555-Z 
[6] Sobkowiak, A., Roberts, M.R., Younesi, R., Ericsson, T., Haggstrom, L., Tai, C.W., Andersson, A.M., Edstrom, K., Gustafsson, T. and Bjorefors, F. (2013) Understanding and Controlling the Surface Chemistry of $\mathrm{LiFeSO}_{4} \mathrm{~F}$ for an Enhanced Cathode Functionality. Chemistry of Materials, 25, 3020-3029.

https: //doi.org/10.1021/cm401063s

[7] Mauger, A. and Julien, C.M. (2017) Critical Review on Lithium-Ion Batteries: Are They Safe? Sustainable? Ionics, 23, 1933-1947.

https://doi.org/10.1007/s11581-017-2177-8

[8] Wang, X., Chen, D., Yang, Z., Zhang, X., Wang, C., Chen, J., Zhang, X. and Xue, M. (2016) Sodium-Ion Batteries: Novel Metal Chalcogenide SnSSe as a High-Capacity Anode for Sodium-Ion Batteries. Advanced Materials, 28, 8786-8789.

https://doi.org/10.1002/adma.201670278

[9] Wang, J., Chen, M., Chen, H., Luo, T. and Xu, Z. (2012) Leaching Study of Spent Li-ion Batteries. Procedia Enviromental Sciences, 16, 443-450.

https://doi.org/10.1016/j.proenv.2012.10.061

[10] Kang, J., Senanayake, G., Sohn, J. and Shin, S.M. (2010) Recovery of Cobalt Sulfate from Spent Lithium Ion Batteries by Reductive Leaching and Solvent Extraction with Cyanex 272. Hydrometallurgy, 100, 168-171.

https://doi.org/10.1016/j.hydromet.2009.10.010

[11] Lee, C.K. and Rhee, K.I. (2002) Preparation of $\mathrm{LiCoO}_{2}$ from Spent Lithium-Ion Batteries. Journal of Power Sources, 109, 17-21. https://doi.org/10.1016/S0378-7753(02)00037-X

[12] Chen, X. and Zhou, T. (2014) Hydrometallurgical Process for the Recovery of Metal Values from Spent Lithium-Ion Batteries in Citric Acid Media. Waste Management and Research, 32, 1083-1093. https://doi.org/10.1177/0734242X14557380

[13] Swamy, K.M. and Narayana, K.L. (2001) Ultrasonically Assisted Leaching. Advances in Sonochemistry, 6, 141-179. https://doi.org/10.1016/S1569-2868(01)80008-5

[14] Nayaka, G.P., Manjanna, J., Pai, K.V., Vadavi, R., Keny, S.J. and Tripathi, V.S. (2015) Recovery of Valuable Metal Ions from the Spent Lithium-Ion Battery Using Aqueous Mixture of Mild Organic Acids as Alternative to Mineral Acids. Hydrometallurgy, 151, 73-77. https://doi.org/10.1016/j.hydromet.2014.11.006

[15] Golmohammadzadeh, R., Rashchi, F. and Vahidi, E. (2017) Recovery of Lithium and Cobalt from Spent Lithium-Ion Batteries Using Organic Acids: Process Optimization and Kinetic Aspects. Waste Management, 64, 244-254. https://doi.org/10.1016/j.wasman.2017.03.037

[16] Li, L., Zhai, L., Zhang, X., Lu, J., Chen, R., Wu, F. and Amine, K. (2014) Recovery of Valuable Metals from Spent Lithium-Ion Batteries by Ultrasonic-Assisted Leaching Process. Journal of Power Sources, 262, 380-385.

https://doi.org/10.1016/j.jpowsour.2014.04.013 